\title{
Relationship between Folic Acid Supplementation, Serum Homocysteine and Markers of Kidney Function in Male Albino Rats
}

\author{
Maha .A .Al-Qaraawi \\ Department of Biology, Faculty of Sciences at Riyadh, Princess Noura University, Saudi Arabia
}

\begin{abstract}
Increased serum homocysteine (Hcy) can induce kidney diseases and can play a role in renal disorders. The purpose of the present study therefore was to investigate the relationship between serum hyperhomocysteinemia (HHcy) induced by methionine administration, folic acid and kidney functions. The relationship between total homocysteine (tHcy) and outcomes has not been investigated in patients with chronic kidney disease. The present study was designed to induce hyperhomocysteinemia (HHcy) in male rats. Also, to evaluate, the effect of (HHcy) as a risk factor for kidney disorder and folic acid supplementation on serum levels of Hcy, urea, uric acid, creatinine and alkaline phosphatase. In this work 50 male albino rats were used and divided into five groups. The first served as control., the second and third group received two different doses of L-methionine., the fourth and fifth group received fortified diet with folic acid powder plus L-methionine. The results showed that homocysteine levels in rats received low and high doses of methionine were higher than in the control group, and increased urea in rats treated with high dose of methionine only, while uric acid and creatinine level showed insignificant changes in rats treated with both doses of methionine. Alkaline phosohatases activity significantly increased in low and high dose treated rats compared to control group. Folic acid supplementation induced significant decrease in homocysteine level in rats treated with high dose of methionone while low dose keeps homocysteine within normal value.As regard to kidney functions, supplementation of folic acid with low dose of methionine leading to significant decrease in serum urea and uric acid concentration while, when folic acid added to high dose of methionine keep its concentration within the normal value.Creatinine and alkaline phosphatase level significantly increased in folic acid treated rats with high dose of methionine, but an alkaline phosphatase activity significantly increased in folic acid treated rats with low and high dose of methionine. A positive correlation was seen between the activities of alkaline phosphatase in serum and HHcy rats. It can be concluded that hyperhomocysteinemia may be an additional risk factor for renal failure and dietary supplementation with folic acid blocking the activity of homocysteine and may be considered as a therapeutic possibility in patients with renal disorders. Also, plasma Hcy and folic acid measurement may be useful in the evaluation of renal disorders. More studies are necessary to pinpoint the precise mechanisms that lead to hyperhomocysteinemia in renal failure. This should lead to optimal treatment and, ultimately, to the prevention of cardiovascular complications in this vulnerable patient group.
\end{abstract}

Keywords: Homocysteine, folic acid, methionine, renal faliure, renal disorders

\section{Introduction}

Circulating homocysteine, a risk factor for cardiovascular disease (CVD), is often elevated in chronic kidney disease and end-stage renal disease. Little is known about the risk of elevated homocysteine associated with less advanced renal insufficiency in the community(1).

Of the many amino acid abnormalities that are present in chronic renal failure, hyperhomocysteinemia has drawn increasing attention because of its proposed role in the development and/or progression of atherothrombotic disease. Renal function is a major determinant of fasting plasma homocysteine level, and the inverse relationship between the glomerular filtration rate (GFR) and plasma homocysteine level is present throughout the whole range of renal function. Although this suggests an active renal homocysteine metabolism, no important urinary excretion or active homocysteine extraction has been demonstrated in the human kidney. Analysis of plasma concentrations of the various cofactors and substrates of homocysteine metabolism, and the effects of different therapies indicates that an abnormal folate metabolism may be the cause of hyperhomocysteinemia in uremia(2).

According to the multiple regression analysis, the determinants of total homocysteine were only plasma folate, plasma vitamin $\mathrm{B}-12$, and creatinine clearance $(\mathrm{r} 2=0.20)$. In conclusion, a high prevalence of hyperhomocysteinemia was found in our sample of nondialyzed patients with CKD. The determinants of total homocysteine levels were plasma folate, plasma vitamin B-12, and creatinine clearance. No association between nutritional parameters and total homocysteine was observed (3). Data are limited on the determinants of homocysteine (tHcy) and its relationship with nutritional indices, and dietary protein intake, in the early stages of chronic kidney disease (CKD) (4).

The study of (5) reported that elevated serum homocysteine levels appear to be closely associated with CKD. Serum homocysteine levels are negatively associated with GFR Hyperhomocystinemia does not appear to be a risk factor for all-cause or CVD mortality in the Modification of diet in renal disease study. Prior studies demonstrating an association between tHcy and CVD risk may have inadequately adjusted for the confounding effects of kidney function (6) Significant positive correlations were found between concentrations of ADMA, homocysteine and creatinine also between age and creatinine (7).

The apparent lack of efficacy of vitamin therapy in most of the large clinical trials was probably determined by the failure to take account of the metabolic deficiency of vitamin B12, which is very common and often missed, and by the failure to take account of impaired renal function( 8 ). 


\section{International Journal of Science and Research (IJSR) \\ ISSN (Online): 2319-7064}

Index Copernicus Value (2013): 6.14 | Impact Factor (2015): 6.391

Hyperhomocysteinemia has been linked with various atherosclerotic diseases, but has not been evaluated sufficiently as a risk factor for the development of chronic kidney disease (CKD) in the general population (9).

\section{Materials and Methods:}

\section{Chemicals}

1-L-Methionine : supplied by Sigma - Aldrich Company.

The chosen dose was $1 \mathrm{~g} / \mathrm{kg} \mathrm{b}$ wt(10).

2- Folate: supplied by Sigma -Aldrich Company. The chosen dose was $19 \mathrm{~g} / \mathrm{kg}$ diet (11).

\section{Animal groups:}

The study was conducted on 50 male albino rats, weighing $200 \mathrm{~g}$. Rats were maintained on commercial rat chow and water ad libitum and allowed to adapt to the prevailing environment for two weeks prior to the beginning of the experiment in the laboratory.

The animals were divided into equal five groups as follows:

- The first group (I): served as a control group.

- The second group (II) received L- methionine in a dose of $1 \mathrm{~g} / \mathrm{kg}$ b wt dissolved in drinking water to induce hyperhomocysteinemia(HHcy)].

- The third group(111) received L- methionine in doses $2 \mathrm{~g} / \mathrm{kg}$ dissolved in drinking water to induce hyperhomocysteinemia (10)

- The fourth group $(1 \mathrm{~V})$ received L- methionine in doses $1 \mathrm{~g} / \mathrm{kg}$ dissolved in drinking water and supplemented with folic acid in a dose $19 \mathrm{~g} / \mathrm{kg}$ diet (11).

- The fifth group (V) received L- methionine in doses $2 \mathrm{~g} / \mathrm{kg}$ dissolved in drinking water and supplemented with folic acid in a dose $19 \mathrm{~g} / \mathrm{kg}$ diet (11).

\section{Sample preparation}

Blood samples were collected at the end of the experimental period ( 8 weeks) for biochemical analysis. Blood samples were obtained from the retro-orbital sinus of an over night fasted rats under light ether anesthesia according (12), then centrifuged. The separated sera were analyzed for estimation of, homocysteine (13), urea, uric acid, ceatinine and alkaline phosphatase activity.

\section{Statistical Analysis:}

The data were analyzed using SPSS program version 16.The analysis of covariance (one way ANOVA) was used to detect the differences in the mean between the treated groups and the control and between the supplemented group with folate and methionine treated groups. The mean differences are significant at $\mathrm{P}<0.05$.

\section{Results}

The results showed that homocysteine levels in rats received low and high doses of methionine were higher than in the control group ( table 1\&figure 1), and increased serum urea in rats treated with high dose of methionine only, while uric acid and creatinine level showed insignificant changes in rats treated with both doses of methionine (table 2, 3 \&figure 2, 3). Alkaline phoshatase activity significantly increased in low and high dose treated rats compared to control group (table 4 \&figure 4). Folic acid supplementation induced significant decrease in homocysteine level in rats treated with high dose of methionone while low dose keeps homocysteine within normal value.As regards to kidney functions, supplementation of folic acid with low doses of methionine leading to significant decrease in serum urea and uric acid concentration while, when folic acid added to high dose of methionine keep its concentration within the normal value.Creatinine and alkaline phosphatase level significantly increased in folic acid treated rats with high dose of methionine, but and alkaline phosphatase activity significantly increased in folic acid treated rats with low and high dose of methionine. A positive correlation was seen between the activities of alkaline phosphatase in serum and HHcy rats.

Table 1: Serum homocysteine levels $(\mathrm{mg} / \mathrm{dl})$ of male rats in the control and different treated groups

\begin{tabular}{|c|c|c|c|}
\hline \multirow{2}{*}{ Group } & \multicolumn{3}{|c|}{ Homocysteine (mg/dl) } \\
\cline { 2 - 4 } & $\begin{array}{c}\text { Mean } \\
\pm \text { S.E }\end{array}$ & $\begin{array}{c}\text { (Ta) } \\
\text { Significant } \\
\text { Test }\end{array}$ & $\begin{array}{c}\text { (Tb) } \\
\text { Significant } \\
\text { Test }\end{array}$ \\
\hline 1- Control & $11.74 \pm 0.870$ & ----- & $0.001^{*}$ \\
\hline $\begin{array}{c}\text { 2- Treated with 1g/kg.B.W. } \\
\text { Methionine. }\end{array}$ & $42.65 \pm 5.075$ & $0.001^{*}$ & ----- \\
\hline $\begin{array}{c}\text { 3- Treated with 2g/kg.B.W. } \\
\text { Methionine. }\end{array}$ & $54.84 \pm 6.838$ & $0.001^{*}$ & ----- \\
\hline $\begin{array}{c}\text { 4- Treated with 1g/kg } \\
\text { B.W. methionine and supplemented with } \\
\text { folic acid. }\end{array}$ & $42.01 \pm 2.781$ & $0.001^{*}$ & 0.912 \\
\hline $\begin{array}{c}\text { 5- Treated with 2g/kg } \\
\text { B.W. methionine and supplemented with } \\
\text { folic acid. }\end{array}$ & $29.54 \pm 2.106$ & $0.001^{*}$ & $0.001^{*}$ \\
\hline
\end{tabular}

The mean difference is significant at the 0.05 level

(Ta): significant as compared with normal control group.

(Tb): significant as compared with the same dose of methionine treated group. 


\section{International Journal of Science and Research (IJSR) ISSN (Online): 2319-7064}

Index Copernicus Value (2013): 6.14 | Impact Factor (2015): 6.391

Table 2: Serum urea, uric acid levels (mg/dl)of male rats In the control and different treated groups.

\begin{tabular}{|c|c|c|c|c|c|c|}
\hline Groups & \multicolumn{3}{|c|}{ Urea (mg/dl) } & \multicolumn{3}{|c|}{ Uric acid (mg/dl) } \\
\hline & Mean \pm S.E & $\begin{array}{c}\mathrm{Ta}) \\
\text { Significant test }\end{array}$ & $\begin{array}{c}(\mathrm{Tb}) \\
\text { Significant test }\end{array}$ & Mean \pm S.E & $\begin{array}{c}\text { (Ta) Significant } \\
\text { Test }\end{array}$ & $\begin{array}{l}\text { (Tb) Significant } \\
\text { Test }\end{array}$ \\
\hline 1- Control rats & $19.11 \pm 1.511$ & & 0.165 & $4.34 \pm 0.212$ & & ......... \\
\hline $\begin{array}{l}\text { 11- Rats treated with } 1 \mathrm{~g} / \mathrm{kg} \text {. } \\
\text { methionine }\end{array}$ & $22.65 \pm 1.584$ & 0.165 & $\ldots \ldots \ldots$ & $4.90 \pm 0.308$ & 0.169 & .. \\
\hline $\begin{array}{l}\text { 111- Rats treated with } 2 \mathrm{~g} / \mathrm{kg} \text {. } \\
\text { methionine }\end{array}$ & $25.21 \pm 2.375$ & $0.020^{*}$ & & $4.75 \pm 9.394$ & 0.308 & ........ \\
\hline $\begin{array}{l}\text { 1V- Rats treated with } 1 \mathrm{~g} / \mathrm{kg} \text {. } \\
\text { methionine \& folic acid }\end{array}$ & $15.93 \pm 1.362$ & 0.210 & $0.011^{*}$ & $6.23 \pm .134$ & $0.000^{*}$ & $0.002 *$ \\
\hline $\begin{array}{l}\text { V- Rats treated with } 2 \mathrm{~g} / \mathrm{kg} \text {. } \\
\text { methionine \& folic acid }\end{array}$ & $25.38 \pm 1.812$ & $0.017 *$ & 0.947 & $5.01 \pm 0.291$ & 0.100 & 0.515 \\
\hline
\end{tabular}

The mean difference is significant at the 0.05 level

(Ta): significant as compared with normal control group.

(Tb): significant as compared with the same dose of methionine treated group.

Table 3: Serum creatinine level (mg/dl)of male rats In the control and different treated groups.

\begin{tabular}{|c|c|c|c|}
\hline $\begin{array}{c}\text { Groups } \\
\text { Parameters }\end{array}$ & \multicolumn{3}{|c|}{ Creatinine (mg/dl) } \\
\hline & Mean \pm S.E & $\begin{array}{c}(\mathrm{Ta}) \\
\text { Significant T } \\
\text { test }\end{array}$ & $\begin{array}{c}(\mathrm{Tb}) \\
\text { Significant T } \\
\text { test }\end{array}$ \\
\hline 1- Control rats & $0.60 \pm 0.038$ & ----- & 0.793 \\
\hline $\begin{array}{c}11-\text { Rats treated with } \\
\text { g/kg. methionine }\end{array}$ & $0.65 \pm 0.045$ & 0.793 & ----- \\
\hline $\begin{array}{c}111-\text { Rats treated with } \\
\text { 2g/kg. methionine }\end{array}$ & $0.62 \pm 0.317$ & 0.759 & \\
\hline $\begin{array}{c}1 \mathrm{~V}-\text { Rats treated with } \\
1 \mathrm{~g} / \mathrm{kg} \text {. methionine\& } \\
\text { folic acid }\end{array}$ & $0.65 \pm 0.018$ & 0.407 & 0.570 \\
\hline $\begin{array}{c}\mathrm{V}-\text { Rats treated with } \\
2 \mathrm{~g} / \mathrm{kg} \text {. methionine \& } \\
\text { folic acid }\end{array}$ & $0.82 \pm 0.057$ & $0.000^{*}$ & $0.001^{*}$ \\
\hline
\end{tabular}

The mean difference is significant at the 0.05 level

(Ta): significant as compared with normal control group.

(Tb): significant as compared with the same dose of methionine treated group.

Table 4: Serum alkaline phosphatase level (mg/dl)of male rats in the control and different treated groups

\begin{tabular}{|c|c|c|c|}
\hline $\begin{array}{c}\text { Groups } \\
\text { Parameters }\end{array}$ & \multicolumn{3}{|c|}{ Alkaline phosphatase (mg/dl) } \\
\hline & Mean \pm S.E & $\begin{array}{c}\text { (Ta) } \\
\text { Significant } \\
\text { test }\end{array}$ & $\begin{array}{c}(\mathrm{Tb}) \\
\text { Significant } \\
\text { test }\end{array}$ \\
\hline 1- Control rats & $158.29 \pm 22.034$ & $\begin{array}{c}\ldots \ldots \ldots \ldots \\
\ldots \ldots \ldots\end{array}$ & $\begin{array}{c}\ldots \ldots \ldots \ldots \\
\ldots \ldots \ldots\end{array}$ \\
\hline $\begin{array}{l}\text { 11- Rats treated with } \\
1 \mathrm{~g} / \mathrm{kg} \text {. methionine }\end{array}$ & $237.49 \pm 20.449$ & $0.006^{*}$ & $\begin{array}{c}\ldots \ldots \ldots \ldots \\
\ldots \ldots \ldots \\
\end{array}$ \\
\hline $\begin{array}{l}\text { 111- Rats treated with } \\
2 \mathrm{~g} / \mathrm{kg} \text {. methionine }\end{array}$ & $230.75 \pm 14.786$ & $0.012 *$ & $\begin{array}{l}\ldots \ldots \ldots \ldots \\
\ldots \ldots \ldots \ldots\end{array}$ \\
\hline $\begin{array}{l}1 \mathrm{~V} \text { - Rats treated with } \\
1 \mathrm{~g} / \mathrm{kg} \text {. methionine } \& \\
\text { folic acid }\end{array}$ & $362.12 \pm 20.064$ & $0.000 *$ & $0.000 *$ \\
\hline $\begin{array}{l}\mathrm{V} \text { - Rats treated with } \\
2 \mathrm{~g} / \mathrm{kg} \text {. methionine \& } \\
\text { folic acid }\end{array}$ & $253.88 \pm 18.038$ & $0.001 *$ & $0.001 *$ \\
\hline
\end{tabular}

The mean difference is significant at the 0.05 level

(Ta): significant as compared with normal control group.

(Tb): significant as compared with the same dose of methionine treated group.

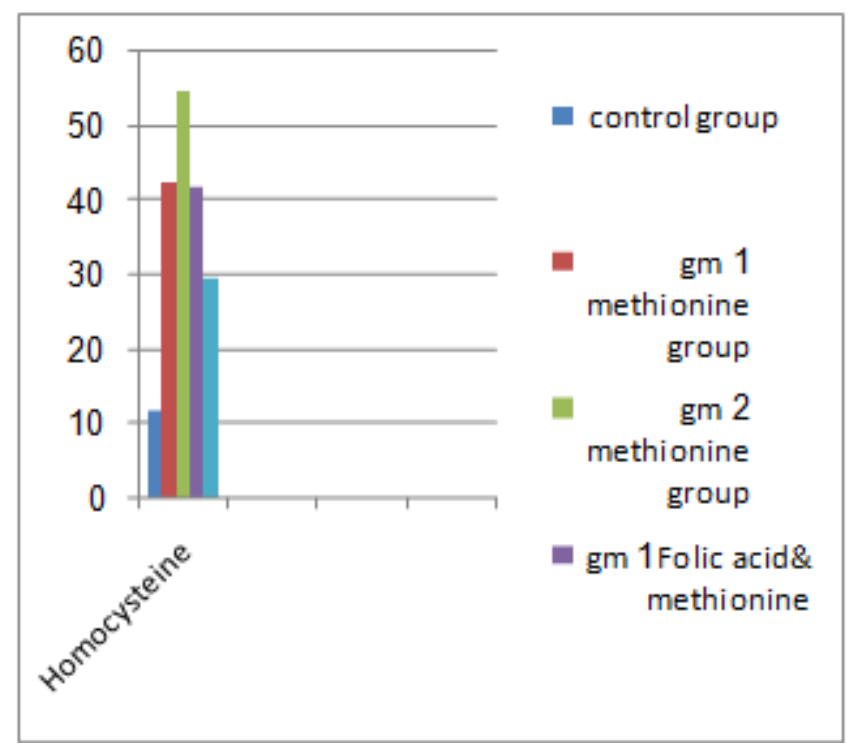

Figure 1: Serum homocysteine levels $(\mathrm{mg} / \mathrm{dl})$ of male rats in the control and different treated



Figure 2: Serum urea and uric acid concentration $(\mathrm{mg} / \mathrm{dl})$ of male rats in the control and different treated groups

\section{Volume 5 Issue 6, June 2016 www.ijsr.net}




\section{International Journal of Science and Research (IJSR) \\ ISSN (Online): 2319-7064}

Index Copernicus Value (2013): 6.14 | Impact Factor (2015): 6.391

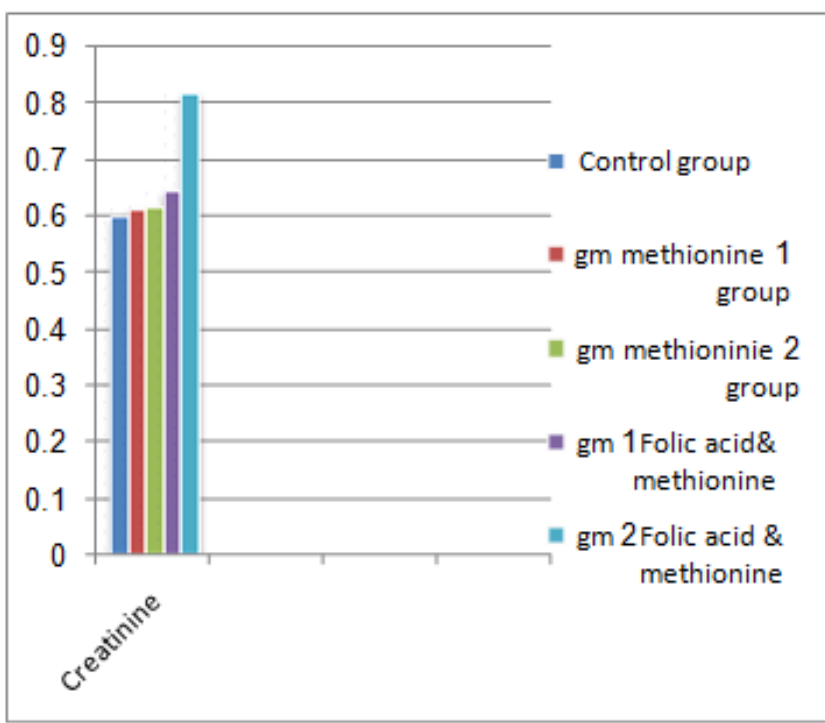

Figure 3: Serum creatinine concentration $(\mathrm{mg} / \mathrm{dl})$ of male rats in the control and different treated groups

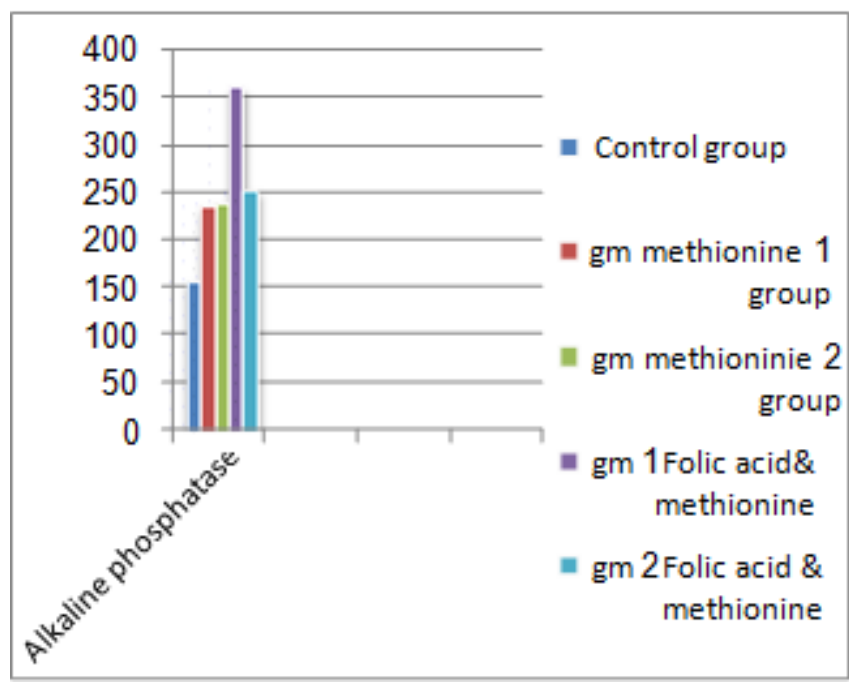

Figure 4: Serum alkaline phosphatese activity $(\mathrm{mg} / \mathrm{dl})$ of male rats in the control and different treated groups

\section{Discussion}

The results showed that homocysteine levels in rats received low and high doses of methionine were higher than in the control group, and increased urea in rats treated with high dose of methionine only, while uric acid and creatinine level showed an insignificant increase in rats treated with both dose of methionine. Alkaline phoshatases activity significantly increased in low and high dose treated rats compared to control group. Folic acid supplementation induced significant decrease in homocysteine level in rats treated with high dose of methionone while low dose keeps homocysteine within normal value.As regard to kidney functions, supplementation of folic acid with low doses of methionine leading to significant decrease in serum urea and uric acid concentration while, when folic acid added to high dose of methionine keep its concentration within the normal value.Creatinine and alkaline phosphatase level significantly increased in folic acid treated rats with high dose of methionine, but and alkaline phosphatase activity significantly increased in folic acid treated rats with low and high dose of methionine. A positive correlation was seen between the activities of alkaline phosphatase in serum and HHcy rats

Hyperhomocysteinemia is a disorder of methionine metabolism, it may be frequently due to nutrient oral deficiencies, particularly low folate status (14).

Plasma concentrations of homocysteine are controlled by two metabolic pathways : the remethylation and transulfuration pathways. Remethylation of homocysteine requires the enzymes 5, 10 - methylenetetrahydrofolate reductase (5.10-MTHFR) and methionine synthase. Transulfuration is dependent on cytathionine B-synthase (CBS) enzyme activity. Deficiencies in any of these enzymes and/or increased substrate for HCY metabolism elevat in metabolized intracellular HCY, which is exported from the cell into plasma (15). It is unclear whether decreased remethylation is also responsible for other abnormalities of homocysteine metabolism in renal failure, such as the exaggerated rise and the impaired decline of plasma homocysteine concentration after methionine or homocysteine loading. More studies are necessary to pinpoint the precise mechanisms that lead to hyperhomocysteinemia in renal failure(2).

The study of (16) reported that plasma homocysteine in three different groups of patients with chronic renal failure and the clearance of homocysteine as a percentage of creatinine clearance was also significantly increased compared to controls. Thus the clearance of homocysteine was not affected to the same extent as that of creatinine in renal failure. This may be attributed to the fact that, besides the reduced glomerular filtration rate, a depressed tubular uptake of homocysteine may occur in chronic renal failure. However, after methionine loading in eight patients with severe chronic renal failure, a slight but significant increase of plasma homocysteine was noted.

The marked significant increase in serum urea with high dose of methionine, accompanied by insignificant increase in uric acid and creatinine level in rats treated with both doses of methionine was consistent with the finding of (7) who reported that, a significant positive correlations were found between concentration of homocysteine and creatinine and age and creatinine.Also, the adverse effect of hyperhomocysteinemia on the vascular wall can be explained by increasing plasma concentration of dimethylarginine, a potent inhibitor of nitric oxide synthase.

The findings of (9) suggest that elevated serum tHcy levels are a significant risk factor for the development of chronic kidney disease in the general population. The results of (17) showed that higher plasma concentrations of Hcy after acute exercise are independent of vitamin status, or amino acid metabolic stress but could be related to potential changes in renal function.

In accordance with the present study (18) who suggest that hyperhomocysteinemia and elevated lipoprotein level increased with declining renal function, and $58 \%$ of patients with a glomerular filtration rate less than $10 \mathrm{Ml} / \mathrm{min}$ had both HHcy and elevated lipoprotein (a) levels. 


\section{International Journal of Science and Research (IJSR) \\ ISSN (Online): 2319-7064}

Index Copernicus Value (2013): 6.14 | Impact Factor (2015): 6.391

Plasma tHcy concentration is affected by several physiological factors and is elevated under conditions of impaired folate and cobalamin status and in renal failure, and the increase in the tHcy was more strongly associated with changes in serum folate than in serum creatinine, suggesting an altered folate status (19). Insignificant increase in serum creatinine may be due to decreased glomerular rate, creatinine secretion and clearance.Also, the increase in serum urea and uric acid concentrations was considered to have a harmful effect on the community, and may be attributed to decrease in the urinary excretion of uric acid.( 20).

In the present study alkaline phosohatase activity significantly increased in rats treated with low and high dose of methionine compared to control group.

These results are in accordance with (21) who showed that ALP levels returned to the normal range by treating the underlying lesions involving the kidney: nephrectomy, complete removal of stones, or removal of nephrostomy. The increase in serum ALP activity may be derived from the injury to the brush border membrane of the renal tubular cells. Renal function impairment and contrast media induced nephrotoxicity may also be responsible for the increased serum ALP. Serum ALP may be a marker for involvement of the kidneys in pathological processes and an indicator of complete treatment. Higher ALP has been recently associated with increased mortality and coronary calcification in dialysis patients. In pre-dialysis chronic kidney disease patients, this association is not clear(22).

The results indicate that glomerular and tubular parameters may be influenced by hyperhomocysteinemia and may cause renal dysfunction. With large doses of methionine, the tubular cells become swollen and contain altered mitochondria, causing impaired oxidative and phosphorolative abilities. This may be responsible for the decrease in absorption and secretory function of the proximal tubular cells (23). This may explain our results.

Folic acid supplementation induced significant decrease in homocysteine level in rats treated with high dose of methionone while low dose keeps homocysteine within normal value.As regards to kidney functions, supplementation of folic acid with low doses of methionine leading to significant decrease in serum urea and uric acid concentration while, when folic acid added to high dose of methionine keep its concentration within the normal value.Creatinine and alkaline phosphatase level significantly increased in folic acid treated rats with high dose of methionine, but alkaline phosphatase activity significantly increased in folic acid treated rats with low and high dose of methionine. A positive correlation was seen between the activities of alkaline phosphatase in serum and HHcy rats.

Findings from the present study indicate that HHcy with low independently impair vascular function. Mechanisms responsible for these observations are that HHCY increase oxidative stress in general and vascular $\mathrm{O} 2$ in particular. HHcy unleashes mediators of inflammation such as $\mathrm{Nf}$ kappa B, IL-lbeta, IL-6, and IL-8, increases production of intracellular superoxide anion causing oxidative stress and induces endoplasmic reticulum (ER) stress, which can explain many processes of Hcy promoted cell injury such as apoptosis, fat accumulation and inflammation, and ER stress may be involved in kidney diseases (24).

The mechanism of HHcy induced acceleration of lipid peroxidation leading to organelle membrane dysfunction and subsequent cell injury and death. Also HHcy catalyzed generation of reactive oxygen species which is responsible for initiating the peroxidative reaction.

These findings indicate that the elevated level of plasma Hcy may be indicative of much broader and deeper alteration in intracellular methylation dysfunction, and suggest that dietary enrichment with folic acid is essential for the metabolism of Hcy, especially in adult animals (25). Hcy is a sulfur containing amino acid produced during metabolisms of methionine. elevated Hcy impairs vascular function, including impairment of endothelial function, production of Reactive oxygen species (Ros) and consequent oxidation of low density lipids.

Folic acid required for remethylation of Hcy to methionine, are the most important dietary determinants of hyperhomocysteinemia and daily supplementation lowers plasma Hcy levels. Homocysteine levels are significantly increased in liver transplant recipients, therefore a specific treatment with folate in patients after renal transplantation might reduce the risk of complications resulting from HHcy ( 26 ). Also, the results of ( 27) show that homocysteine levels are increased in chronic renal insufficiency, but may be lowered by folate enhancement of the remethylation of homocysteine to methionine. Since elevated plasma homocysteine is associated with premature vascular disease, folic acid may reduce cardiovascular risk in chronic renal insufficiency. Both folic acid doses induced a significant and similar decrease in plasma Hcy in subjects with moderatesevere chronic renal failure. The possible dose-related effect of this approach in reducing the risk of accelerated sclerotic vascular disease and cardiovascular events in this especially vulnerable population should be a matter of further investigation.

In patients with renal insufficiency, elevated tHcy plasma levels are detected in $50-100 \%$ of the patients. Total homocysteine plasma levels can be lowered or normalised by folic acid and/or vitamin $\mathrm{B}(6)$ and vitamin $\mathrm{B}(12)$ supplementation. In patients with advanced chronic renal insufficiency or end-stage renal disease, hyperhomocysteinaemia is partially resistant to folic acid or vitamin therapy. However, higher tHcy plasma levels may also reflect tissue damage and the increase in Hcy after an acute incident such as stroke or myocardial infarction may be necessary for tissue repair mechanisms. This implies, that lowering tHcy may even be harmful to some patients. Currently, prospective studies are underway to clarify whether folate supplementation, with or without additional other vitamins, improves cardiovascular disease morbidity and mortality in the general population, as well as in renal failure patients. While population-wide screening for and treatment of hyperhomocysteinemia is generally not recommended, treatment of high risk patients may be considered.(28). 


\section{International Journal of Science and Research (IJSR) \\ ISSN (Online): 2319-7064}

Index Copernicus Value (2013): 6.14 | Impact Factor (2015): 6.391

Disagreement with the present study The causes of hyperhomocysteindemia in renal failure remain obscure. The possibilities include impairment of both renal and extrarenal metabolic pathways by uraemia. Hyperhomocysteindemia is associated in some, but not all studies with an increased risk for cardiovascular disease. A low homocysteine may reflect malnutrition and predict a poor outcome. Folate achieves modest reductions of homocysteine in some, but not all studies. There are no data to support therapy with very highdose folic acid. Hyperhomocysteindemia impairs endothelial function which is not adequately reversed by folate(29).

It is concluded that supplementation with 2.5 or $5 \mathrm{mg}$ folic acid has a similar effect on homocysteine concentrations to supplementation regimens using $15 \mathrm{mg}$ folic acid supplements. In contrast to the effect of folic acid supplementation in subjects with normal renal function, folic acid supplementation does not normalize homocysteine concentrations in end stage renal disease(1).

In agreement with the present study ( 30) folic acid treatment lowers, but does not normalize plasma homocysteine, whereas homocysteine remethylation and methionine transmethylation increase to levels found in untreated healthy controls. In the general population, renal insufficiency is strongly associated with an increased risk of elevated circulating homocysteine, independent of B vitamin status. These results raise the possibility that elevated homocysteine may be an important risk factor to explain the heavy burden of CVD associated with kidney disease.

On conclusion, these results suggest that mean total Hcy levels increased with kidney diseases and association between Hcy and renal function parameters raises the possibility that these circulating factors could interact to potentiate a process that affect kidney and causes renal failure. Also, the finding of the present research showed a correlation between homocysteine levels, folic acid, which gives information that hyperhomocysteinemia probably due to vitamin deficiencies. Folic acid, required for remethylation of homocysteine to methionine, is the most important dietary determenants of homocysteine and daily supplementation typically lowers plasma homocysteine levels and decreasing plasma Hcy levels through diet may be paralleled by a reduction in renal diseases.

\section{References}

[1] Francis ME, Eggers PW, Hostetter TH, Briggs JP (2004). Association between serum homocysteine and markers of impaired kidney function in adults in the United States. Kidney Int. ;66(1):303-12.

[2] van Guldener C, Stam F, Stehouwer CD (2001)Homocysteine metabolism in renal failure. Kidney Int Suppl.;78:S234-7.

[3] Nerbass FB, Draibe SA, Feiten SF, Chiarello PG, Vannucchi H, Cuppari L (2006) Homocysteine and its determinants in nondialyzed chronic kidney disease patients. J Am Diet Assoc. ;106(2):267-70.

[4] Menon V, Wang X, Greene T, Beck GJ, Kusek JW, Selhub J, Levey AS, Sarnak MJ.(2005). Homocysteine in chronic kidney disease: Effect of low protein diet and repletion with B vitamins. Kidney Int. ;67(4):1539-46.
[5] Chao MC, Hu SL, Hsu HS, Davidson LE, Lin CH, Li CI, Liu CS, Li TC, Lin CC, Lin WY.( 2014). Serum homocysteine level is positively associated with chronic kidney disease in a Taiwan Chinese population. J Nephrol.;27(3):299-305.

[6] Menon V, Sarnak MJ, Greene T, Wang X, Pereira AA, Beck GJ, Kusek JW, Selhub J, Collins AJ, Levey AS, Shlipak MG.( 2006). Relationship between homocysteine and mortality in chronic kidney disease.;113(12):1572-7.

[7] (Siroká R, Trefil L, Rajdl D, Racek J, Rusnáková H, Cibulka R, Eiselt J, Filipovský J.(2005). Asymmetric dimethylarginine, homocysteine and renal function--is there a relation? Clin Chem Lab Med. ;43(10):1147-50.

[8] Spence JD ${ }^{\text {(2013) }}$. B vitamin therapy for homocysteine: renal function and vitamin B12 determine cardiovascular outcomes. Clin Chem Lab Med. 1;51(3):633-7.

[9] Ninomiya T, Kiyohara Y, Kubo M, Tanizaki Y, Tanaka K, Okubo K, Nakamura H, Hata J, Oishi Y, Kato I, Hirakata H, Iida M.( 2004). Hyperhomocysteinemia and the development of chronic kidney disease in a general population: the Hisayama study. Am J Kidney Dis. ;44(3):437-45.

[10] Papandreou, D.; Rousso, I.; Malindretos, P.; Makedou, A. and Arvanitidou, M.(2010): Effects of oral folate supplementation on serum total homocysteine and cholesterol levels in hyperhomocysteinemic children. Nutr. Clin. Pract. 25(4):390-3.

[11] Givvimani, S.;Sen, U.;Tyagi, N. ;Munjal, C. and Tyagi SC.(2011):X-ray imaging of differential vascular density in MMP-9-/-, PAR-1-/+, hyperhomocysteinemic(CBS-/+) and diabetic(ins2/+)mice. Arch. Physiol Biochem. 117(1):1-7.

[12] Blasco, C.; Caballeria, J.; Deulofeu, R. ;Lligona, A.; Pares, A. ; Lluis, JM.; Gual, A. and Rodes, J. (2005):Prevalence and mechanisms of hyperhomocysteinemia in chronic alcoholics. Alcohol Clin. Exp. Res. 29(6):1044-8.

[13] Bosy-Westphal, A. ; Ruschmeyer, M. ; Czech, N. ; Oehler, G. ; Hinrichsen, H. ;Plauth, M. ; Lotterer, E. ; Fleig, W. and Muller, MJ.(2003):Determinants of hyperhomocysteinemia in patients with chronic liver disease and after orthotopic liver transplantation. Am J Clin Nutr. 77(5):1269-77.

[14] Remkova, A. and Remko, M. (2009) : Homocysteine and endothelial markers are increased in patients with chronic liver diseases. Eur J intern Med. 20(5):482-6.

[15] Symons, JD. ;Rutledge, JC.; Simonsen, U. and Pattathu, RA. (2006): Vascular dysfunction produced by hyperhomocysteinemia is more severe in the presence of low folate. Am $\mathrm{J}$ Physiol Heart Circ Physiol.290(1):H181-91.

[16] Hultberg B, Andersson A, Sterner G.(1993). Plasma homocysteine in renal failure. ClinNephrol. ;40(4):2305.

[17] Venta R, Cruz E, Valcárcel G, Terrados N(2009). Plasma vitamins, amino acids, and renal function in postexercise hyperhomocysteinemia. Med Sci Sports Exerc. ;41(8):1645-51.

[18] Darren S. Parsons, David A. Reaveley, Darrell V. Pavitt, and Edwina A. Brown (2002). Relationship of renal function to homocysteine and lipoprotein(a) 
levels: The frequency of the combination of both risk factors in chronic renal impairment. Am J Kidney Dis 40:916-92.

[19] Ozmen B, Ozmen D, Parildar Z, Mutaf I, Turgan N, Bayindir O.(2006). Impact of renal function or folate status on altered plasma homocysteine levels in hypothyroidism. Endocr J. ;53(1):119-24.

[20] Leibovitch I, Ben-Chaim J, Ramon J, Goldwasser B.(1991). Increased serum alkaline phosphatase activity: a possible indicator of renal damage. J Clin Lab Anal. ;5(6):406-9.

[21] Kovesdy CP, Ureche V, Lu JL, Kalantar-Zadeh K.(2010). Outcome predictability of serum alkaline phosphatase in men with pre-dialysis CKD. Nephrol Dial Transplant. ;25(9):3003-11.

[22] Mitra PK, Tasker PR, Ell MS( 2007). Chronic kidney disease. BMJ. 16;334(7606):1273.

[23] Hunter, D.(1975); The disease of occupation. $5^{\text {th }}$ ed. Little, Brown and Co. Boston.

[24]Ji, C. and Kaplowitz, N.(2003): Betaine decreases hyperhomocysteinemia, endoplasmic reticulum stress, and liver injury in alcohol-fed mice. Gastroenterology. 124(5): 1488-99.

[25] Stam $F^{1}$, van Guldener C, Ter Wee PM, Jakobs C, de Meer K, Stehouwer CD ( 2005). Effect of folic acid on methionine and homocysteine metabolism in end-stage renal disease. Kidney Int. ;67(1):259-64

[26] Wilcken DE, Dudman NP, Tyrrell PA, Robertson MR (1988). Folic acid lowers elevated plasma homocysteine in chronic renal insufficiency: possible implications for prevention of vascular disease. Metabolism. ;37(7):697701.

[27] Bernasconi AR, Liste A, Del Pino N, Rosa Diez GJ, Heguilén RM.(2006). Folic acid 5 or $15 \mathrm{mg} / \mathrm{d}$ similarly reduces plasma homocysteine in patients with moderate-advanced chronic renal failure. Nephrology (Carlton). ;11(2):137-41.

[28] Sunder-Plassmann G, Winkelmayer WC, Födinger M.(2000). Therapeutic potential of total homocysteinelowering drugs on cardiovascular disease. Expert OpinInvestig Drugs. ;9(11):2637-51.

[29] Gonin JM.(2005). Folic acid supplementation to prevent adverse events in individuals with chronic kidney disease and end stage renal disease. CurrOpinNephrolHypertens. ;14(3):277-81.

[30] Dierkes J, Domröse U, Ambrosch A, Bosselmann HP, Neumann KH, Luley C.(1999). Response of hyperhomocysteinemia to folic acid supplementation in patients with end-stage renal disease. ClinNephrol. ;51(2):108-15. 